\title{
Studies of Highly Dispersed Titanium Carbide Powder Obtained from Scrap Tungstenless Cemented Carbide Alloys
}

\author{
V. Gavrish ${ }^{1, a}$, T. Chayka ${ }^{1, b^{*}}$, N. Cherkashina ${ }^{2, c}$ and O. Gavrish ${ }^{1, d}$
}

${ }^{1}$ Sevastopol State University, 33 Universitetskaya Street, Sevastopol, 299053, Russia

${ }^{2}$ Belgorod State Technological University named after V.G. Shoukhov, Kostyukovstr., Belgorod,308012, Russia

avmgavrish@sevsu.rul, ${ }^{\mathrm{D} K i m C h a y k a @ y a n d e x . r u, ~}{ }^{\mathrm{C}}$ cherkashina.ni@bstu.ru, dolga_gavrish_53@mail.ru

Keywords: Titanium Carbide, Highly Dispersed Powder, Carbide Waste

\begin{abstract}
The results of research of characteristics of highly dispersed titanium carbide powder obtained from carbide waste of TN-20, TN-25, TN-30 types are presented. The powder particles were studied using analytical methods including scanning microscopy, X-ray diffraction, differential thermal analysis. The obtained results confirm the formation of nanosized particles of titanium carbide of monocrystalline form.
\end{abstract}

\section{Introduction}

Titanium carbide is one of the most demanded materials widely used in industry, modern engineering and medicine [1-3]. The wide range of applications is due to the unique combination of chemical and physical properties of titanium carbide (high wear resistance, corrosion resistance, chemical inertness, high melting point, flexural modulus, etc.) [4-7]. The use of high-dispersity titanium carbide powders (micro- and nanopowders), which provide a significant improvement of the properties of materials based on titanium carbide, is becoming increasingly important [8-11]. The most studied methods of titanium carbide nanopowders production are chemical vapor deposition, self-propagating high-temperature synthesis with laser ignition, sol-gel method, selfpropagating high-temperature synthesis, etc. [12-16]. All these methods are characterized by very low productivity and rather high cost of the final product. Increasing industrial use makes it necessary to reconsider the attitude to the methods of production of titanium carbide nanopowder both in terms of ensuring its high dispersity and purity and in terms of productivity, energy intensity and economy of its production technology.

In this regard, an alternative technological approach is the production of highly dispersed $\mathrm{TiC}$ powders from titanium-containing carbide waste by the technology [17]. This method offers ample opportunities for the production of nanopowders on an industrial scale, as it is characterized by minimal technological equipment, environmental safety, rather low operating costs and competitive prices.

\section{Experimental part}

The powder obtained from the scrap of titanium hard alloys of TN-20, TN-25, TN-30 grades was investigated. The chemical composition is presented in Table 1. 
Table 1. Chemical composition of initial raw materials for obtaining titanium carbide powder

\begin{tabular}{|l|c|c|c|c|c|}
\hline \multirow{2}{*}{ Alloy grade } & \multicolumn{5}{|c|}{ Component content in titanium alloy scrap, mass \% } \\
\cline { 2 - 6 } & $\mathrm{TiC}$ & $\mathrm{Ni}$ & $\mathrm{Mo}$ & $\mathrm{Nb}$ & $\mathrm{WC}$ \\
\hline TN-20 & 79.0 & 14,0 & 6.0 & 0,05 & 0,95 \\
\hline $\mathrm{TN}-25$ & 74.0 & 19,3 & 6.0 & 0.01 & 0.69 \\
\hline TN-30 & 70.0 & 22,5 & 7.0 & - & 0.50 \\
\hline
\end{tabular}

The main component of the slab is titanium carbide TiC cemented by nickel-molybdenum bond $(\mathrm{Ni}+\mathrm{Mo})$, there are also small impurities of niobium $(\mathrm{Nb})$ and tungsten carbide $(\mathrm{WC})$. As a result of treatment of alloys by technology [17] specially prepared dispersing solutions, there is a destruction of the alloy matrix and particle refinement due to the improvement of the machining process.

The crystalline structure of the fillers was investigated by X-ray diffraction (ARL X'TRA, ThermoTechno) with $\mathrm{CuK} \alpha$ source in the $2 \theta$ angle range from 4 to $56^{\circ}$ in asymmetric coplanar mode with sliding angle of incidence $\alpha=30$ ( $\theta$-scan). Phase identification and peak indexing were performed using the ICDD (International Centre for Diffraction Data) PDF-2 database.

The microstructure of the obtained powder was studied using a scanning electron microscope "TESCAN MIRA 3 LMU" (Poland).

For the analysis of the particle size we used the Particle Metric software of the scanning electron microscope PHENOM proX (Phenom-World B.V. (Netherlands).

Differential thermal analysis of the powder was carried out on a NETZSCH STA 449F1. Thermal analysis of the powder was carried out in a platinum crucible in an argon atmosphere in the temperature range of $25 \ldots 1000^{\circ} \mathrm{C}$ at heating of $10^{\circ} \mathrm{C}$ per minute.

\section{Analysis of experimental results}

Fig. 1 shows a diffractogram of the powder obtained from carbide scrap.

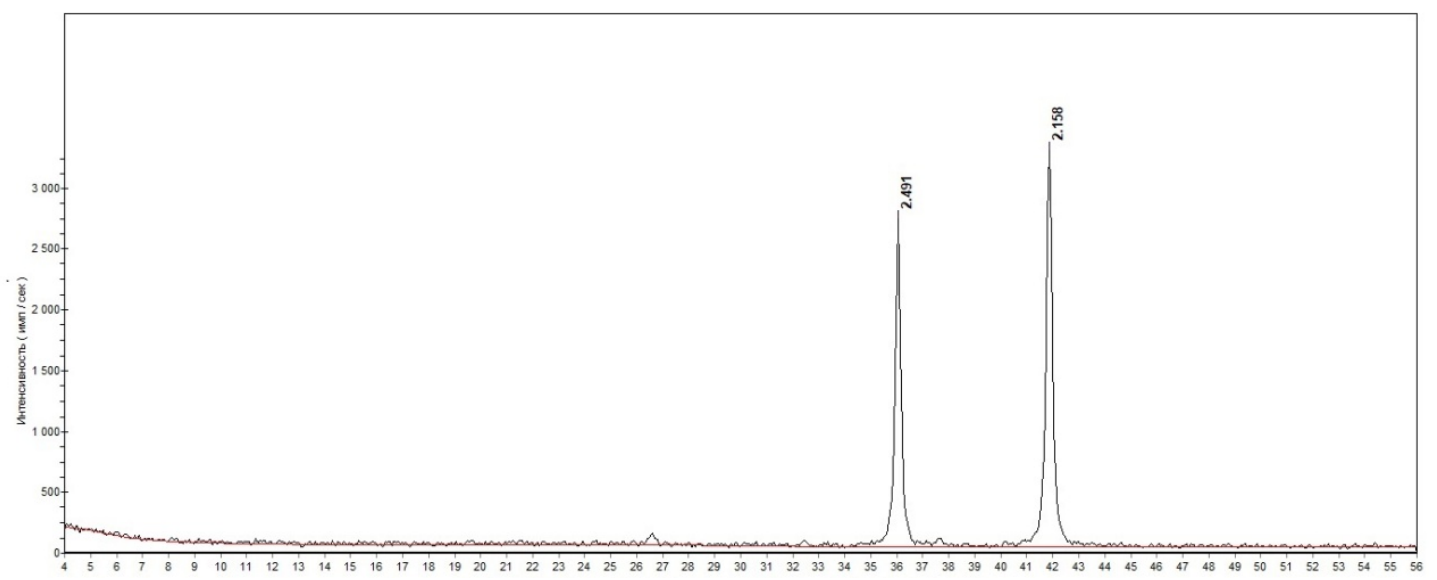

Fig. 1. Powder diffractogram

Two characteristic reflexes at angles $2 \theta 36$ and $42^{\circ}$, which correspond to pure titanium carbide, are present on the X-ray image (PDF card No. 31-1400).

The microstructure of the powder is shown in Fig. 2 

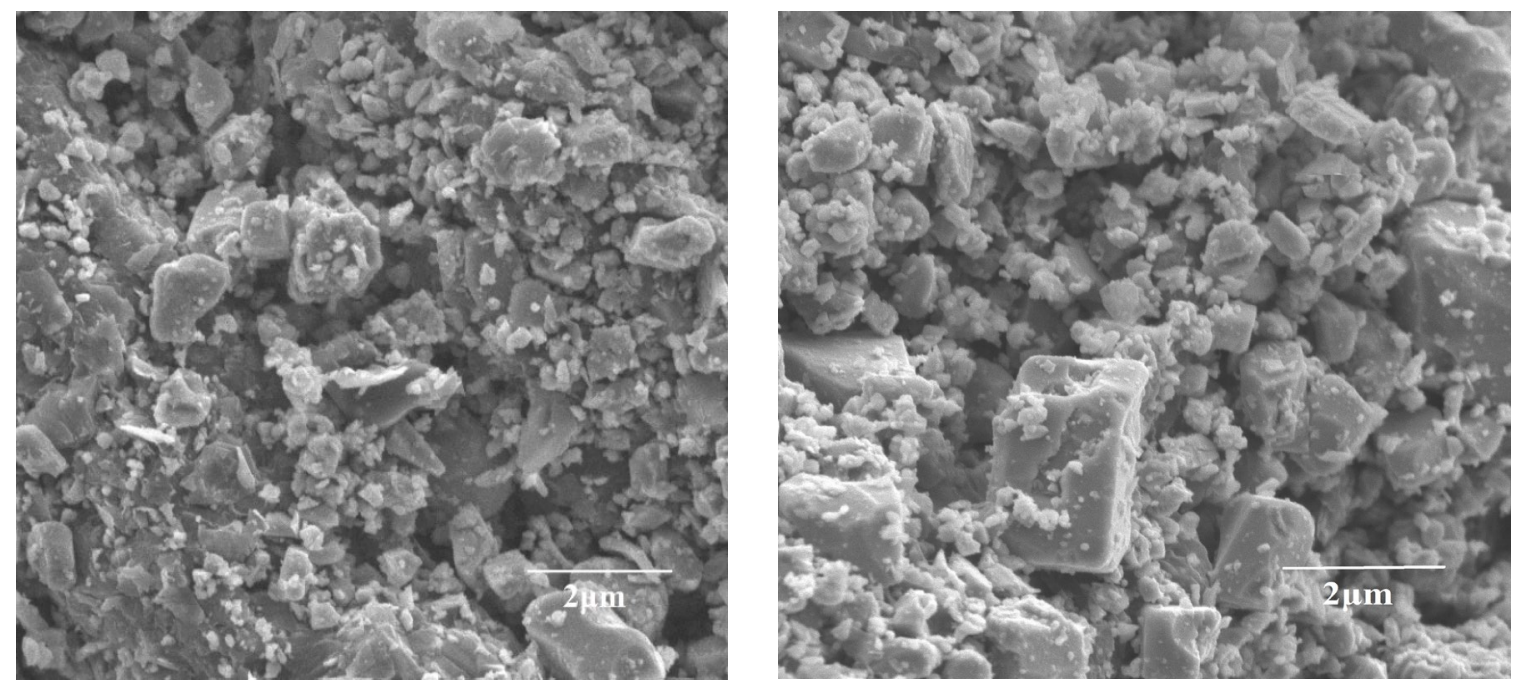

Fig. 2. Microstructure of titanium carbide (TiC) powder

As can be seen from the presented microphotographs (Fig. 2) the powder under study is prone to agglomeration. The microstructure of the particles is heterogeneous, the particle shape is irregular. The average particle size is $60-150 \mathrm{~nm}$, the size of agglomerates is $200 \mathrm{~nm}-2.5 \mu \mathrm{m}$ (Fig. 3).

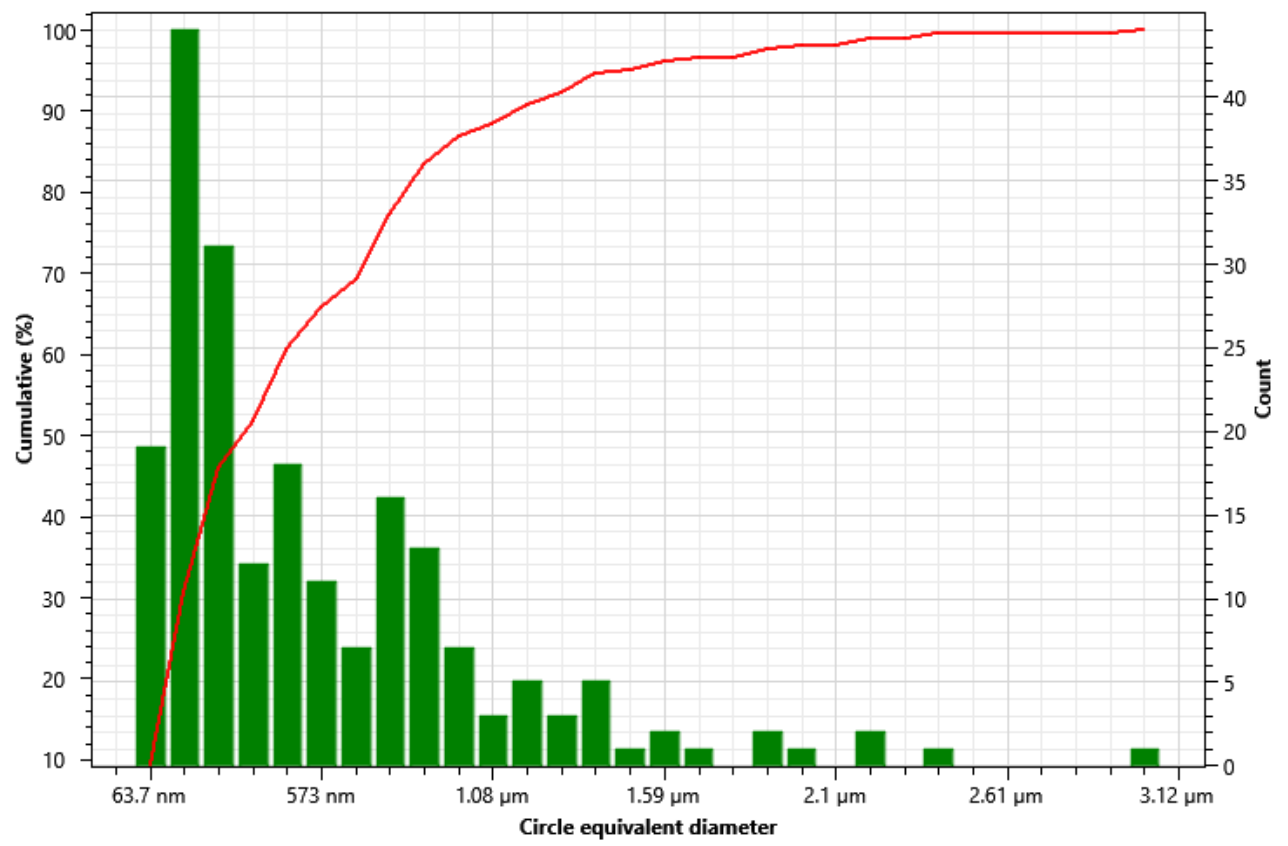

Fig. 3. Titanium carbide powder particle size distribution.

Elemental analysis of the powder (Fig. 4) showed the presence of impurities of molybdenum and tungsten, which is associated with the initial composition of raw materials used for the synthesis of titanium carbide powder. 




Fig. 4. Results of spectral analysis of titanium carbide powder

Differential thermal analysis (DTA) and thermogravimetric analysis (TGA) of the powder under study are shown in Figure 5.

Analysis of the thermogravimetric curve analysis (Fig. 5) showed that when increasing the temperature to $1000{ }^{\circ} \mathrm{C}$ the sample practically does not lose mass $(-0.32 \%)$, indicating its relatively stable behavior in this temperature range. The endothermic process peaks at $133.1{ }^{\circ} \mathrm{C}$, associated with the removal of adsorbed water. Differential thermal analysis (DTA) results indicate the presence of two exothermic effects with peaks at $441.9{ }^{\circ} \mathrm{C}$ and $476.4{ }^{\circ} \mathrm{C}$. The first peak is associated with the oxidation of free carbon, with a loss of mass, the second peak indicates the oxidation of titanium carbide. The increase in mass during oxidation of the sample begins at 476.4 ${ }^{\circ} \mathrm{C}$ and is $1.26 \%$ up to $900{ }^{\circ} \mathrm{C}$, which indicates partial oxidation.



Fig. 5. TGA and DTA curves of titanium carbide (TiC) powder 


\section{Conclusions}

The powder obtained from TN 20, TN-25, TN-30 carbide wastes contains single-phase titanium carbide and impurities of molybdenum and tungsten. The carbide particles have the size of $60 \ldots 150$ $\mathrm{nm}$ and are mainly agglomerated. The particle size of agglomerates is $200 \mathrm{~nm} \ldots 2.5 \mu \mathrm{m}$. It is relatively stable in the high temperature range.

Thus, titanium carbide powder obtained from carbide wastes can be used as an alternative to those available on the market as a component in the production of heat-resistant hard alloys, reinforced alloys, abrasive materials, coatings for cutting tools, etc., but this requires further research.

\section{References}

[1] A.N. Zhigach, I.O. Leipunsky, M.L. Kuskov, N.G. Berezkina, E.S. Afanasenkova, O.A. Safronova, B.V. Kudrov, G.W. Lopez, E.A. Skryleva, Synthesis of pure titanium carbide and titanium carbide/hydride core-shell nanoparticles via the flow-levitation method, and their characterization, J. Alloys and Compounds. 819 (2020) 153054.

https://doi.org/10.1016/j.jallcom.2019.153054

[2] A.M. Elshazli, R.N. Elshaer, A.H.A. Hussein, S.R .Al-Sayed, Laser Surface Modification of TC21 $(\alpha / \beta)$ Titanium Alloy Using a Direct Energy Deposition (DED) Process, J. Micromachines. 12 (2021) 739. https://doi.org/10.3390/mi12070739

[3] S.N. Grigoriev, A.B. Nadykto, M.A.Volosova, A.A. Zelensky, P.M. Pivkin, WEDM as a Replacement for Grinding in Machining Ceramic $\mathrm{Al}_{2} \mathrm{O}_{3}$-TiC Cutting Inserts, J. Metals.2021, 11 (2021) 882. https://doi.org/10.3390/met11060882

[4] S.C. Mojaki, Shivani B. Mishra, Ajay K. Mishra, Synthesis, characterization and material properties of titanium carbide nanocomposite derived from biochar, J. Materials Letters. 264 (2020) 127317. https://doi.org/10.1016/j.matlet.2020.127317

[5] Sreetama Ghosh, PremRanjan, AneeshKumaar, R. Sarathi, SundaraRamaprabhu, Synthesis of titanium carbide nanoparticles by wire explosion process and its application in carbon dioxide adsorption, J. Alloys and Compounds. 794 (2019) 645-653.

https://doi.org/10.1016/j.jallcom.2019.04.299

[6] S. Nam, H.W. Lee, I.-H. Jung, Y.-M. Kim, Microstructural Characterization of TiC-

Reinforced Metal Matrix Composites Fabricated by Laser Cladding Using FeCrCoNiAlTiC High Entropy Alloy Powder, J. Appl. Sci. 11 (2021) 6580. https://doi.org/10.3390/app11146580

[7] Y. Li, D. Zhang, H. Wang, W. Cong, Fabrication of a TiC-Ti Matrix Composite Coating Using Ultrasonic Vibration-Assisted Laser Directed Energy Deposition: The Effects of Ultrasonic Vibration and TiC Content. J. Metals. 11 (2021) 693.

https://doi.org/10.3390/met1 1050693

[8] D. Kiesler, T. Bastuck, R. Theissmann, et al. Plasma synthesis of titanium nitride, carbide and carbonitride nanoparticles by means of reactive anodic arc evaporation from solid titanium, J. Nanopart Res. 17 (2015) 152. https://doi.org/10.1007/s11051-015-2967-8

[9] Hyunho Shin, Jun-Ho Eun, Titanium Carbide Nanocrystals Synthesized from a Metatitanic Acid-Sucrose Precursor via a Carbothermal Reduction, J. Nanomaterials. 2015 (2015) 469121. https://doi.org/10.1155/2015/469121 
[10] P.N. Karakizis, D.I. Pantelis, G. Fourlaris, et al. The role of SiC and TiC nanoparticle reinforcement on AA5083-H111 friction stir welds studied by electron microscopy and mechanical testing. Int J AdvManuf Technol. 94 (2018) 4159-4176.

https://doi.org/10.1007/s00170-017-1147-7

[11] J.M. Kim, J.S. Park, H.S. Yun, Microstructure and Mechanical Properties of TiC Nanoparticle-Reinforced Iron-Matrix Composites, J. Strength Mater. 46 (2014) 177-182. https://doi.org/10.1007/s11223-014-9533-y

[12] Sławomir Dyjak, Małgorzata Norek, Marek Polański, Stanisław Cudziło, Jerzy Bystrzycki, A simple method of synthesis and surface purification of titanium carbide powder, Int. J.

Refractory Metals and Hard Materials. 38 (2013) 87-91. https://doi.org/10.1016/j.ijrmhm.2013.01.004

[13] Mohsen Mhadhbi, MiloudDriss, Titanium Carbide: Synthesis, Properties and Applications, J. Brilliant Engineering. 2 (2021) 1-11. https://doi.org/10.36937/ben.2021.002.001

[14] A. P. Amosov, A. R. Samboruk, A. A. Samboruk, A. A. Ermoshkin, D. V. Zakamov, and K. S. Krivolutskii, Self Propagating High Temperature Synthesis of Titanium Carbide Nanopowder from the Granulated Charge, J. Non Ferrous Metals. 56(1) (2015) 79-85.

https://doi.org/10.3103/S1067821215010034

[15] L.Y. Fedorov, I.V. Karpov, A.V. Ushakovet al. Influence of pressure and hydrocarbons on carbide formation in the plasma synthesis of TiC nanoparticles. J. Inorg Mater. 51 (2015) 25-28. https://doi.org/10.1134/S0020168515010057

[16] N. RahnemaiHaghighi, R. Poursalehi, Effect of $\mathrm{C} / \mathrm{H}$ and $\mathrm{C} / \mathrm{O}$ ratios on the arc discharge synthesis of titanium carbide nanoparticles in organic liquids, J. ApplNanosci.9 (2019)411-421. https://doi.org/10.1007/s13204-018-00946-7

[17] EP 3138932 (A1) EC 